\title{
Multidimensional Scaling Research in Vocational Psychology
}

\author{
James B. Rounds, Jit. \\ State Universisy of New York at Buffalo \\ Michael A. Zevon \\ Rosmell Park Memorial Instinture
}

\begin{abstract}
This review summarizes and evaluates the use of multidimensional scaling in vocational psychology. Multidimensional scaling applications are found in two primary areas: vocational interests and occupational perceptions. These areas correspond to the two major uses of multidimensional scaling: configural verification and dimensional identification. Two issues - the relationship between multidimensional scaling and alternative data analytic methods, and the selection of occupational stimuli-are discussed. A number of developing areas for the application of multidimensional scalling are identified.
\end{abstract}

Multidimensional scaling (MDS) refers to a class of techniques that are used to investigate the structure underlying data. More specifically, the technique organizes proximity data by portraying the similarities among a set of objects as spatial relationships. Although MDS techniques have a wide range of potential applications, the purpose of the present discussion is to summarize and to evaluate the use of these techniques in vocational research.

It is not unusual for a considerable period of time to elapse between the introduction of a new statistical method and its application to substantive issues in a scientific discipline. Although the algorithms for metric (Torgerson, 1952, 1958) and nonmetric (Kruskal, 1964) MDS have been available for approximately three decades, the extensive

APPLIED PSYCHOLOGICAL MEASUREMENT

Vol. 7, No. 4, Fall 1983, pp. 491-510

(C) Copyright 1983 Applied Psychological Measurement Inc. 0146-6216/83/040491-20\$2.25 application of MDS to research in the behavioral sciences is a much more recent phenomenon. Even more recent is the use of MDS in vocational psychology. An examination of this literarure shows that systematic applications of MDS have occurred primarily in two areas, vocational interests and occupational perceptions. These areas have been chosen as central to this review. The decision was buttressed by several prior reviews (Gottredson, 1982; Holcomb \& Anderson, 1977) that identified vocational interests as the dominant research area in vocational psychology. Vocational perceptions, the other area characterized by programmatic MDS applications, is also treated at length. ${ }^{1}$

In organizing the discussion two major purposes for using MDS will be considered: configural verification and dimensional identification. In configural verification the investigator examines the fit between proximity data and prior expectations about the nature of the stimulus configuration. To exemplify this approach, the focus will be on the

\footnotetext{
'The specific studies reviewed herein were assembled by identifying a number of major outlets for vocational research and applications of MDS. These sources included, but were not limited to, the Journal of Vocational Behavior, Applied Psychological Measurement, Journal of Applied Psychology, Journal of Counseling Psychology, Multivariate Behavioral Research, Journal of Occupational Psychology. Personnel Psychology, and Organizational Behavior and Human Performance. These journals were revicwed for the period 1970 to 1983 for reports of research which applied MDS to vocational topics.
} 
structure-of-interest models and the use of factorial and hierarchical methods as alternative data analytic methods for configural verification.

Next, dimensional applications of MDS in the occupational perceptions area will be discussed. The purpose of dimensional applications is to identhe the attributes that individuals attend to in responding to a class of stimuli. The underacknowledged use of MDS in this area has important implications for the understanding of vocational behavior. Using the research on occupational perceptions as an example, the sampling of occupational titles will be discussed.

Finally, a number of promising applications of MDS will be discussed. Although only limited work has been accomplished in these areas to date, the discussion will identify directions for future research and applications of MDS.

\section{Connangyng}

\section{Vocational Interests}

Past and current research on vocational interesus has focused almost exclusively on their measurement, classification, and structure. Furthermore, much of what is reliably known about the structure and classification of vocational irterests is based on factor analytic methods (Dawis, 1980). Roe's (1956) and Holland's (1973) strucure-of-interest models, for example, can be traced directly to Guilford, Christensen, Bond, and Sutton's (1954) factor analysis of 33 interest scales. This initial and influential study of the interest domain identified seven vocational interest factors (Mechanical, Scientific, Social Welfare, Aesthetic Expression, Clerical, Business, and Outdoor Work) as equivalent across two air corps samples. As detailed by Rounds and Dawis (1979), these Guilford factors were the most explicit forerumers of Roe's eight interest fields and Holland's six interest types.

A representation of Roe's circular model of interest fields and Holland's hexagonal model of interest types is shown in Figure 1. Although Roe (1956; Roe \& Klos, 1969) hypothesized an overall circular ordering, the intemal relationships among the interest finds were never specified. Holland's hexagonal model, on the ofher hand, defines the internal relationships among the interest types such that the distances between the types are "inversely proportional to the theoretical relationships between them" (Holland, 1973, p.5), i.e., adjacent types on the hexagon are most related, whereas opposite types are least related, with alternating types of an intermediate level of relationship.

As a result of the apparent similarity of Holland's and Roe's models, Holland (1976) and Lunneborg (1975) have suggested a parallelism between com. ponents of the models. Specifically, the following elements are hypothesized to represent similar domains: Holland's Realistic (R) and Roe's Technology (Te) and Outdoor (Od); Holland's Investigative (I) and Roe's Science (Sc); Holland's Artistic (A) and Roe's General Cultural (GC) and Arts and Entertainment (AE); Holland's Social (S) and Roe's Service (Sv); Holland's Enterprising (E) and Roe's Business Contact (Bu); and Holland's Conven tional (C) and Roe's Organization (Or).

Studies of Roe's and Holland's structural models. Strong support for both the circular and hexagonal structure-of-interest models has been provided by the application of principal components analyses to intercorrelation matrices based on interest scale scores (e.g., Hanson \& Cole, 1973; Prediger, 1982). The use of MDS analysis with similar sets of data has, on the other hand, provided only equivocal support for these models. Meir (Feldman \& Meir, 1976; Meir, 1973; Meir, Bar, Lahav, \& Shalhevet, 1975; Meir \& Ben-Yehuda, 1976) has conducted a series of MDS studies examining the fit of the internal relationships among scores on a Hebrew interest inventory (Ramak; Meir \& Barak, 1974) and the Hebrew version of the Self-Directed Search (SDS; Holland, 1972) to Roe's circular and Holland's hexagonal models, respectively. In each study the structure was tested with Israeli subjects by means of the Gutman-Lingoes Smallest Space Analysis (SSA-耳; Gutman, 1968; Lingoes, 1965).

In one of the first applications of MDS to interest data, Meir (1973) examined the fit of Roe's fieldby-level model to the intercorrelations among Ramak scale scores. This model classifies occupations according to three levels of function and

Downloaded from the Digital Conservancy at the University of Minnesota, http://purl.umn.edu/93227. May be reproduced with no cost by students and faculty for academic use. Non-academic reproduction requires payment of royalties through the Copyright Clearance Center, http://www.copyright.com/ 
Figure $\mathbb{1}$

Schematic Representations of Roe's Circular Model and Holland's Hexagonal Model

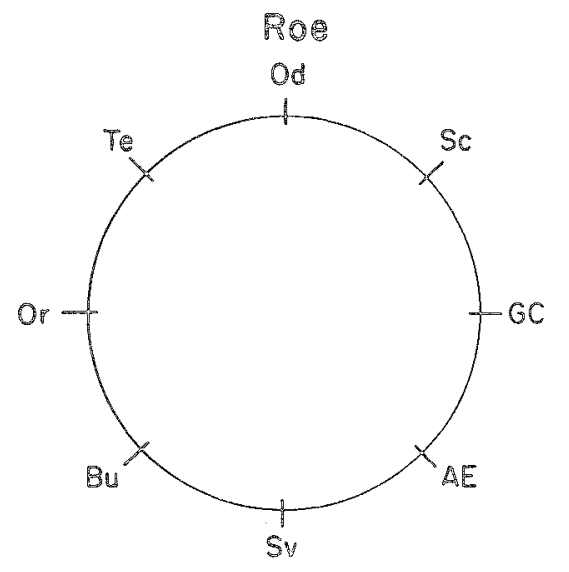

eight fields defined by their primary focus of activity. The Ramak interest inventory was scored by three levels and eight fields for a total of 24 scale scores. As shown in Table 1, the arrangement of the felds in two-dimensional space for the 12 thgrade female and male students did not conform to Roe's circular ordering of interest fields. A visual inspection of the configurations shows that these scale points formed a horseshoe shape with the $\mathrm{Te}$ and Sc scale points and the Or and $\mathbb{B} u$ scale points clustering together. Although the three levels for each tended to cluster within fields, the order of the levels was not in the hypothesized sequence. As can be seen from Table 1, two subsequent studies by Meir and his associates produced slightly different Ramak configurations, none of which match the Roe circular ordering of interest fields.

Meir has also examined the fit of Holland's RIASEC hexagonal model to the internal relationships among two measures of Holland's interest types, i.e., the Interest Inventory for Females (IIF) and the Hebrew translation of the SDS. For the III, Feldman and Meir (1976) reported circular orderings of IRAESC for a female 11 th-grade sample and an IRASEC circular ordering for an employed female sample. There was considerable overlap of the scale points representing the $S$ and $E$ interest fields for both samples. For the Hebrew version of the SDS, Meir and Ben-Yehuda (1976)
Holland

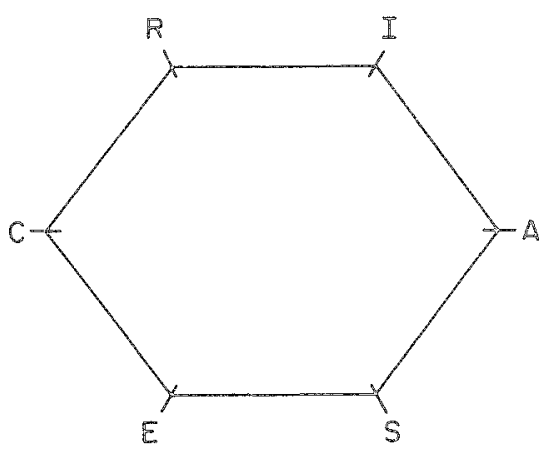

reported a two-dimensional horseshoe-shaped configuration of RISACE with the R-I, S-A, and C-E scale points clusiering together for a combined sample of male and female ninth-grade students.

Feldman and Meir's (1976) finding that the Holland model for females was IRAESC or IRASEC was not confirmed in a study with American subjects (Rounds, Davison, \& Dawis, 1979). Using TORSCA-9 nonmetric scaling (Young \& Torgerson, 1967), Rounds et al. (1979) examined the fit of the Strong-Campbell Interest Inventory (SCII) and the Vocational Preference Inventory (VPI) scales to Holland's hexagonal model. As shown in Table 1 , five scaling solutions were obtained with an identical RIASEC scale arrangement. Nevertheless, a visual examination and a statistical test (Wakefield \& Doughtie, 1973) of how well the scaling representation fit the model showed that the female data met the expectations from Holland's model less often than the male data. The fit of the SCII MDS results to the hexagonal model for females was not good, with a near reversal of the $\$$ and $\mathrm{E}$ scales. For males the fit of the SCII and VPI MDS results to the hexagonal model was satisfactory.

When reviewing the above studies, it is apparent that the MDS research by Meir and his colleagues (Feldman \& Meir, 1976; Meir, 1973; Meir et al., 1975; Meir \& Ben-Yehuda, 1976) provides no sup- 
Table 1

Multidimensional Scaling Studies of Vocational Interests

\begin{tabular}{|c|c|c|c|}
\hline Study & Instruments & Subjects ${ }^{1}$ & $\begin{array}{l}\text { Polygonal } \\
\text { Scale order }\end{array}$ \\
\hline \multirow[t]{2}{*}{ Meir (1973) } & \multirow[t]{2}{*}{ Ramak } & $\begin{array}{l}12 t h-\text { grade Israeli } \\
\text { students } \\
(N=296, F)\end{array}$ & $\begin{array}{l}\mathrm{Te}-\mathrm{Sc}=\mathrm{Od}-\mathrm{AE}- \\
\mathrm{Sv}-\mathrm{GC}=\mathrm{Or}-\mathrm{Bu}\end{array}$ \\
\hline & & $\begin{array}{l}12 \text { th }=\text { grade Israeli } \\
\text { students } \\
(N=220, M)\end{array}$ & $\begin{array}{l}\mathrm{Te}-\mathrm{Sc}=\mathrm{Od}-\mathrm{AE}- \\
\mathrm{Sv}=\mathrm{GC}-\mathrm{Or}-\mathrm{Bu}\end{array}$ \\
\hline \multirow[t]{4}{*}{$\begin{array}{l}\text { Meirs Sohlberg, } \\
\qquad \text { Barak (1973) }\end{array}$} & Ramak & $\begin{array}{l}\text { 12th-grade Arab } \\
\text { students } \\
(N=170, F \& M)\end{array}$ & $\begin{array}{l}\mathrm{Te}-\mathrm{Od}-\mathrm{AE}-\mathrm{SV}- \\
\mathrm{GC}-\mathrm{Or}=\mathrm{Bu}-\mathrm{SC}\end{array}$ \\
\hline & CII & Same as above & $\begin{array}{l}\mathrm{Te}-\mathrm{SC}-\mathrm{Od}=\mathrm{GC}- \\
\mathrm{AE}-\mathrm{SV}-\mathrm{Bu}=\mathrm{Or}\end{array}$ \\
\hline & Ramak & $\begin{array}{l}\text { Israeli University } \\
\text { applicants } \\
(N=231, F \& M)\end{array}$ & $\begin{array}{l}\text { Te- } S c-O d-S v- \\
A E-G C-O r-B u\end{array}$ \\
\hline & CII & Same as above & $\begin{array}{l}\mathrm{Te}-\mathrm{Sc}-\mathrm{Od}-\mathrm{AE}- \\
\mathrm{GC}-\mathrm{SV}-\mathrm{Or}-\mathrm{Bu}\end{array}$ \\
\hline $\begin{array}{l}\text { Meir, Bar, Lahav, } \\
\text { \& Shalhevet (1975) }\end{array}$ & Ramak/CII & $\begin{array}{l}\text { Israeli Army soldiers } \\
\quad(\mathrm{N}=136, M)\end{array}$ & $\begin{array}{l}\mathrm{Te}-\mathrm{Sc}=\mathrm{Od}-\mathrm{AE}= \\
\mathrm{GC}-\mathrm{Sv}-\mathrm{Or}-\mathrm{Bu}\end{array}$ \\
\hline \multirow[t]{2}{*}{$\begin{array}{l}\text { Feldman \& Meir } \\
\qquad(1976)\end{array}$} & \multirow[t]{2}{*}{$I I F$} & $\begin{array}{l}\text { 1lth-grade Israeli } \\
\text { students }(N=322, \quad F)\end{array}$ & $I-R-A \rightarrow E-S=C$ \\
\hline & & $\begin{array}{l}\text { Israeli workers } \\
\quad(N=167, F)\end{array}$ & $I-R-A-S-E-C$ \\
\hline $\begin{array}{l}\text { Meir \& Ben-Yehuda } \\
\quad(1976)\end{array}$ & $\begin{array}{l}\text { Hebrew SDS/ } \\
\quad \text { Ramak }\end{array}$ & $\begin{array}{l}\text { 9th-grade Israeli } \\
\text { students } \\
(N=217, F \& M)\end{array}$ & $\begin{array}{l}\mathrm{Te}-\mathrm{R}=\mathrm{T}-\mathrm{SC}-\mathrm{Od}-\infty \\
\mathrm{SV}=\mathrm{S}-\mathrm{A}-\mathrm{GC}-\mathrm{AE}- \\
\mathrm{Or}=\mathrm{C}-\mathrm{Bu}-\mathrm{E}\end{array}$ \\
\hline \multirow[t]{3}{*}{ Gati (1979) } & VPI & $\begin{array}{l}\text { College students } \\
\text { from Lunneborg \& } \\
\text { Lunneborg }(1975) ; \\
(N=235, F \& M)\end{array}$ & $R-I-A-S-E=C$ \\
\hline & VII & Same as above & $\begin{array}{l}T e-S c-O d-A E- \\
S v-G C-O r-B u\end{array}$ \\
\hline & VPI/VII & Same as above & $\begin{array}{l}\text { concentric } \\
\text { circles } \\
\text { Te-Od-Sc-AE- } \\
G C-S v-O r-B u \\
R-I-A-S-E-C\end{array}$ \\
\hline \multirow[t]{5}{*}{$\begin{array}{l}\text { Rounds, Davison, } \\
\text { \& Dawis (1979) }\end{array}$} & VPI & $\begin{array}{l}\text { Sample from ACTP } \\
\qquad(1968) ; \quad(\mathrm{N}=2433, F)\end{array}$ & $R-I-A-S-E-C$ \\
\hline & VPI & $\begin{array}{l}\text { 2-year college } \\
\text { freshman from } \\
\text { Ho1land }(\mathbb{1 9 7 3 )} ; \\
(\mathrm{N}=1234, \mathrm{M})\end{array}$ & $R-I-A-S-E-C$ \\
\hline & SCII & $\begin{array}{l}\text { Sample from Campbe11 } \\
\quad(1977) ; \quad(N=201, F)\end{array}$ & $R-I-A-S-E-C$ \\
\hline & SCII & $\begin{array}{l}\text { Sample from Campbell } \\
\quad(1977) ; \quad(N=200, M)\end{array}$ & $R=I-A-S-E-C$ \\
\hline & SCII & $\begin{array}{l}\text { Clients, mean age } 32 \\
(\mathrm{~N}=305, F)\end{array}$ & $R=I-A=S=E-C$ \\
\hline
\end{tabular}

${ }^{1} M=$ Male, $F=$ Female.

Downloaded from the Digital Conservancy at the University of Minnesota, http://purl.umn.edu/93227. May be reproduced with no cost by students and faculty for academic use. Non-academic reproduction requires payment of royalties through the Copyright Clearance Center, http://www.copyright.com/ 
port for Roe and Holland's hypothesized interest configurations. On the contrary, each study has found a different circular ordering of the interest fields and different scale point clusters. Some caution is required, however, when interpreting Meir's inability to replicate the hypothesized interest configurations. On the one hand, it is important to realize that these studies were conducted among different age groups, with the youngest subjects being 14 to 15 years old. On the other hand, and perhaps more importantly, cultural differences may account for the failure to find the hypothesized interest configuration.

A study that addresses the issue of cultural differences and the structure of vocational interests was reported by Meir, Sohlberg, and Barak (1973). The investigation examined the fit of the correlations among the Ramak scales and the Courses Interest Inventory (CII) to Roe's circular configuration with an Arab (nonwestem culture) 12th-grade sample and an Israeli (western culture) university applicant sample. For intercultural comparisons the 12 th-grade Ramak data for both sexes, previously reported by Meir (1973), were reanalyzed. As shown in Table 1 , the arrangement of the Ramak and CII scales does not conform to Roe's hypothesized order, and the Ramak scale order differs from the CII scale order for the Arab and the Israeli samples. Because of the scale order variability within the Arab and Israeli samples, it is almost impossible to accurately summarize the scale order between these samples.

The four interest configurations for the Israeli samples can best be described as "misshapen polygons," a term Holland (1979) applied to the hexagons resulting from real-world data. The two interest configurations for the Arab samples are best represented by a triangle with the $\mathrm{Sc}$ and $\mathrm{Te}$ scales at the apex of the triangle, and the $\mathrm{AE}, \mathrm{Sv}, \mathrm{GC}$, $\mathrm{Or}$, and Bu scales defining the base of the triangle, a configuration that suggests a degenerate solution. At least for these samples the Arab students differentiated the Sc and Te occupations from other occupations more so than did the Israeli students.

The question of the adequacy of the Ramak as a measure of Roe's eight interest fields is one possible explanation for the lack of fir between the Ramak data and Roe's circular model. Since Roe's hypothesized circular model is culturally determined, another plausible explanation concerns the diversity and breadth of American occupations in comparison to Israeli occupations. None of these explanations, however, received support from Gati's (1979) SSA-I of the Vocational Interest Inventory (VII; Lunneborg, 1975) scalle correlations based on male and female American university students. Aside from the Ramak, the VII appears to be the only instrument developed based on Roe's system. Gati has presented an arrangement of Roe's fields that is identical to Meir's (1973) circular arrangement of Te-Sc-Od-AE-Sv-GC-Or-Bu, a finding that leads to questions concerning the adequacy of Roe's model.

Studies comparing Roe's and Holland's models. Two studies (Gati, 1979; Meir \& BenYehuda, 1976) have investigated the parallelism between Holland's and Roe's models. Meir and Ben-Yehuda (1976) displayed a two-dimensional solution with four scale clusters defining two orthogonal dimensions: Sc and Od opposing $\mathrm{E}, \mathrm{C}$, $\mathrm{Bu}$, and $\mathrm{Or}$; and $\mathrm{Te}, \mathbb{R}$, and $I$ opposing $\mathrm{AE}, \mathrm{A}$, $\mathrm{Gc}, \mathrm{Sv}$, and $\mathrm{S}$. In spite of the apparent correspondence between fields, the parallel fields are not always nearest to each other: $\mathrm{Bu}$ lies nearer to $\mathrm{C}$ than to $E$, and $O d$ lies nearer to $S$ than to $R$.

As previously noted, Gati (1979) presented a two-dimensional SSA-I scaling solution of correlational matrices from Lunneborg and Lunneborg's (1975) factor analytic study of the interest models of Roe and Holland. The configuration was a concentric circle with Holland's RIASEC forming the inner circle and Roe's Te-Od-Sc-AE-GC-Sv-OrBu forming the outer circle. This concentric pattern of the interrelationships between Holland and Roe scales is not unexpected; intercorrelations among the Holland scales have previously been found to be quite high, in some instances almost as high as correlations between measures for the same $\mathrm{Hol}$ land interest type (Rounds et al., 1979). Gati (1979) reported that expectations based on parallel fields are not met in several cases: Or is between $\mathrm{Bu}$ and $\mathbb{E}, C$ is nearer to $\mathbb{E}$ than to Or, and $S$ is nearer to $\mathrm{GC}$ than to $\mathrm{SV}$.

Summary. MDS studies of the structure-ofinterests have highlighted several problems of the hexagonal and circular models. With respect to 
Roe's circular model, there is a disagreement between the theoretical and empirical ordering of the interest fields. The inconsistencies in the ordering are usually interchanges of adjacent fields and occur across samples in an unpredictable manner. With respect to Holland's model, the empirical data generally conform to the RIASEC ordering; the shape of the configurations, however, rarely approximates a hexagon. In addition, female data meets the Ilolland model expectations less often than does the male data. Finally, the expected parallelism between Holland and Roe's models has yet to be demonstrated.

The aforementioned less than perfect relationship between interest theory and data led Gati (1979, 1982) to propose that a hierarchical model fits the empirical interrelationships between interest fields more adequately than the circular or hexagonal models. It is important to note that Gati's (1979) inicial claims for a hierarchical model were based on the comparison of MDS or factor analytic soIutions to hierarchical cluster solutions. Gati?'s (1982) most recent claims for a hierarchical model as a better representation of the Holland and Roe data are based on a direct (raw proximity data) comparison of the distances between interest fields. Gati has buttressed his conclusion with arguments that the hierarchical approach offers a more appropriate framework for studying the process of occupational choice and career development. Tversky and Gati (1978) have also questioned the viability of distance measures for psychological similarity (see Krumhansi, 1978, for a response).

The following discussion will examine only Gati's initial claim conceming dimensional, factorial, and hierarchical representation. Although the issue of the appropriateness of specific analytic procedures is pertinent to a number of vocational research areas, the comparison of MDS to other data analytic methods seems best exemplified in the context of vocational interest research.

\section{Hirmensional, Factorial, and Hierarchich

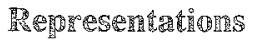

Two issues concerning the relationship between dimensional, factorial, and hierarchical methods will be addressed. The first, more global, issue involves understanding the similarities and differences among these methods. The second and more specific issue is which data analytic techniquenonmetric scaling, principal components, or hierarchical clustering - best accounts for the interrelationships among interest scales.

Comparisons among methods. Comparisons of MDS to factor analysis (Davison, 1983; MacCallum, 1974; Shepard, 1972) and cluster analysis (Kruskal, 1977; Sattath \& Tversky, 1977; Shepard \& Arabie, 1979) have generally focused on the most appropriate type of proximity data for each procedure, the assumptions underlying the analyaic procedures, and the manner in which stimuli are represented. Although all three methods essentially analyze similarity measures, factor analysis, with only a few notable exceptions (e.g., Ekman, 1954), has rarely been used with similarity judgments.

Cluster, factor, and MDS procedures also rest on very different assumptions regarding the relationship between the proximity data and its spatial representation. Nonmetric MDS assumes that the proximity data are a monotonic function of distances between objects in Euclidean space. Factor analysis assumes that the proximity data are linearly related, not to distances between objects, but to cosines of angles between vectors. Hierarchical cluster analysis assumes that the proximity data are monotonically related to distances in ultrametric space (see Davison, 1983, pp. 208-211, for a discussion of the concept of ultrametric distances). Although factor analysis and MDS both provide spatial representations of the stimulus structure, MDS has the advantage of ease of interpretability, i.e., it is easier to interpret distances between points or scale values than to interpret the angles between vectors as required by factor analysis. Hierarchical cluster analysis, on the other hand, represents stimuli in terms of stimulus groups portrayed in a tree diagram. It is important to realize that the tree diagram representation and the spatial representations usually capture different aspects of the same data.

Although these generalizations concerning the comparison of dimensional, factorial, and hierarchical methods provide overall guidelines, Davison 
$(1981,1983)$ has more systematically examined the relationship of factor analysis and MDS. Davison investigated the relationship of nonmetric scaling and principal components solutions based on the same intercorrelation matrices for ability and interest measures. His results suggest that the principal components solution will usually contain a general factor that has no dimensional counterpart in the scaling solution. Scale values, when appropriately transformed, provided a close approximation to the factor loadings. This type of systematic comparison of MDS and factor analysis is an area of increased activity in several psychological domains (Luxenberg \& Zevon, 1982; Zevon, Luxenberg, \& Rounds, 1983).

Utility of the methods. Two specific data analytic methods used in the interest area employ principal component analyses to study the relationships among interest scales. The principal components method used to provide initial support for Holland's circular arrangement of interest fields (e.g., Cole, 1973; Cole, Whitney, \& Holland, 1971; Lumneborg \& Lunneborg, 1975) was a configural analysis or "analysis of spatial configuration" (Cole \& Cole, 1970). Using a two-stage principal components analysis, this method treats variables as vectors and fits a "smaller dimensioned" space to the vectors.

Gati (1979) compared solutions based on configural analysis, Gutrman-Lingoes SSA-I, and ADDTREE hierarchical cluster analysis (Sattath \& Tversky, 1977) in a reanalysis of Lunneborg and Lunneborg's (1975) VPI and VII correlation matrices. The ADDTREE solution was compared to the SSA-I solution via the coefficient of alienation $(C O A)$, an ordinal measure of fit. The COA for the VPI data analyzed with the dimensional methodology was .012, whereas the hierarchically based COA was .075. The dimensional COA for the VII data was .014; the hierarchically based COA was .095. Variance accounted for was used to compare the configural solution to the ADDTREE solution. The values reported for the VPI data were $77.5 \%$ and $68.4 \%$ for the factorial and hierarchical solutions, whereas the corresponding VII values were $75.9 \%$ and $77.1 \%$. These comparisons of the differing representational methods indicate that di- mensional and factorial methods provide a slightly betrer fit than the hierarchical method for the VPI Holland data. For the VII Roe data the hierarchical method represented the distances in the data as well as the dimensional and factorial methods.

Investigations of Holland's hexagonal model no longer employ Cole and Cole's (1970) analysis of spatial configurations. Cooley and Lohnes' (1971, pp. 137-143) FACTOR program, a principal component technique for the extraction of arbitrary factors, has become the dominant method for examining the fit of the interrelationships among interest scales to Holland's RIASEC hexagonal model. The Cooley and Lohnes algorithm allows the researcher to specify a target matrix of loadings. Each factor is extracted in succession with the restriction that each successive factor must be orthogonal to all previously extracted factors. Prediger (1982), using the FACTOR program, examined the extent to which two theory-based dimensions-..data/ideas and things/people-fit 24 sets of Holland scale intercorrelations. He reported the RIASEC scale arrangement for 23 of the 24 data sets.

No direct comparisons exist between solutions resulting from the Cooley and Lohnes (1971) technique and nonmetric scaling procedures. However, Rounds et al. (1979) and Rounds and Dawis (1980) have examined, with the TORSCA-9 scaling program, six of the same data sets found in Prediger (1982). Visuall inspection of these two sets of solutions shows (1) an identical RIASEC circular ordering, (2) a dissimilar configuration for four of the six 2-dimensional solutions, and ( 3 ) a different dimensionality for two of the six solutions. Although no firm conclusions are possible based on this ad hoc comparison, MDS seems to more faithfully reproduce the observed proximity data.

\section{Dirnems}

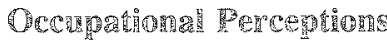

One of the best kept secrets in vocational psy. chology is the extensive MDS research on occupational perceptions. Holland (1973, 1976), for example, reviewed the occupational perceptions literature, yet did not ciee any MDS studies. Like- 
wise, in a review of the empirical evidence supporting career development theories, Osipow (1983) cired studies on occupationall stereotyping but failed to cite any of the MDS studies of occupational perceptions. It should be noted, however, that much of this literature is reported in European journals and/or is conducted within disciplines other than psychology.

\section{Dimensions of Occunational Perceptions}

Perceptions of occupations have been studied under a variety of labels, e.g., vocational or occupational images, stereotypes, and preferences. With the exception of several factor analytic studies (e.g., Gonyea \& Lumneborg, 1963) and the MDS literature, research on how individuals perceive occupations has primarily focused on perceptions of job incumbents (e.g., Dipboye \& Anderson, 1961) or has equated occupational perceptions with responses to interest inventories (e.g., Edwards, Nafziger, \& Holland, 1974). Where direct judged similarities have been used, several additional criteria become salient in investigations of occupational perceptions. First, a large and representative sample of occupations must be studied. Second, the basis for comparison must be chosen by the subject rather than imposed by the investigator. Finally, the method of data analysis must be able to both accommodate large numbers of occupations and to recover the dimensions on which the occupations have been compared.

Studies of occupational stereotypes that purport to investigate occupational perceptions tend to meet none of the above requirements. The typical experimental design involves the a priori manipulation of, at most, two dimensions for only a few occupations and the subsequent assessment of the manipulation on a third dimension (e.g., preference). Studies that have directly investigated the judged similarity of large numbers of occupations rely on either content analysis (e.g., Grunes, 1957) or principal components analysis (e.g., Stone \& Bassett, 1972). In the former case, the descriptive analyses relied on rather arbitrary and intuitive clusters. In the latter case the principal components analyses yielded an unmanageable number of di- mensions, whereas the higher order factors proved too complex for clear and interpretable results. Furthermore, principal components solutions usually employ derived indices of similarity rather than direct similarity judgments, a characteristic that may contribute to a loss of information. Because factor analysis is an unsatisfactory method for analyzing similarity judgments, work on the structure of occupational perceptions was largely abandoned until the development of MDS. MDS, employed on a representative sample, does satisfy the aforementioned criteria.

As is illustrated in Table 2, the bulk of the research in the area of occupational perceptions has been conducted by only a small number of investigators. The most systematic work has been conducted by Reeb $(1959,1971,1974,1979)$ using nonmetric scaling. Reeb has been concerned primarily with identifying the characteristics by which individuals organize occupational perceptions and with examining the generalizability of these dimensions.

Guided by census data, Reeb (1959) selected the 15 most frequently entered occupations for 15 - to 19-year-old males in London. Using a category $\mathrm{T}^{2}$ rating technique, he obtained direct similarity judgments from British Youth Employment Officer trainees. Two dimensions were obtained with Torgerson's $(1952,1958)$ algorithm and were visually interpreted as a craft versus clerical dimension and an occupational level dimension. Using the same MDS technique and set of occupations, Reeb (1971) attempted to replicate his prior findings with experienced British Employment Officers and two groups of 14- to 15-year-old school dropouts of different socioeconomic levels. Instead of direct similarity judgments, however, occupations were judged according to suitability (viz., "For a boy you are advising, if one job of the pair is the most suitable of all possible jobs, then how suitable is the other?"').

Reeb investigated the generality of the MDS representations-and hence the difference between similarity and suitability representations-through a comparison of the solutions based on the 1959 counselor trainee sample and the 1971 experienced counselor sample. The resulting dimensions for the 
combined counselor group were easily interpreted, one being occupational level and the other bluecollar versus while-collar. For the combined adolescent sample, the dimensions were labeled "prestige" and "desirability." The very high correlations between the stimulus coordinates for the two groups of counselors $(r=.92$ for the level dimension and $r=.94$ for the blue/white collar dimension), and between the ratings given on two occasions for the experienced counselors $(r=.98)$, indicate a well-founded perceptual structure unaffected by type of judgment task (similarity versus suitability) or experience. The test-retest reliabilities and subgroup analyses for the male adolescents also indicated a stable and generalizable occupational structure. More importantly, as Reeb (1971) notes, "The most striking result, however, is the extreme simplicity of the dimensional structure ... with advantages in intuitive understanding and in economy and clarity of exposition as to how these groups saw these occupations" (p. 242).

Using M-D-SCAL (Kruskal \& Carmone, 1969) to scale 12 occupational titles, Reeb (1974) partially replicated his 1971 findings with 125 Israeli adolescent boys. The group suitability judgments were found to be highly reliable, and MDS yielded two dimensions unaffected by the subjects" socioeconomic level, intelligence, or job preference. The first dimension, prestige, is similar to that found in Great Britain with adolescent male samples. The second dimension, however-blue collar versus white collar-does not seem to have a counterpart in the dimensional representation of the British adolescents.

Reeb was able to study up to 15 occupations, a level that required a subject to make 105 paired comparison judgments. In contrast, the experimental task in which subjects sort occupations into categories can be used to scale large numbers of occupations without overwhelming subjects. Burton (1972) was able to study 60 occupations with such a sorting task, a maximum determined by the limitations of Kruskal's M-D-SCAL program. Subjects were instructed to sort a deck of cards with occupational terms on them into any number of piles "so that occupations which seemed the same were in the same pile" (Burton, 1972, p. 59).
Scaling of the joint probability measure of occupational similarities indicated three dimensionsdependency, prestige, and skill.

Burton's study, pertaining as it does to only 60 occupations and 54 respondents, is limited in scope. Kraus, Schild, and Hodge (1978), on the other hand, reported the first comprehensive investigation of a large sample of occupations $(N=220)$ and respondents $(N=463)$ representative of, respectively, the occupational domain and the general population. The subject sample included individuals aged 20 and over randomly sampled from the three largest urban areas in Israel. Pretests of the occupational sorting task showed that respondents had difficulty coping with more than approximately 90 occupations. Consequently, Kraus et al. (1978) randomly assigned the respondents to three subsamples. Respondents in each subsample were presented with 90 occupations to sort, 25 of which were common to all subsamples and 65 of which were unique to the three subsamples. The symmetric similarity matrix, the entries of which are the proportion of respondents sorting the two occupations in the same category, was analyzed with the SSA-I program. Correlations between the first and second unrotated stimulus coordinates common to the three random subsamples and four subgroups indicated a unidimensional occupational structure. This single dimension was highly correlated with both the respondents' ratings of the occupations "social standing" $(r=.98)$ and Hartmann's (1975) prior assignment of occupational prestige scores $(r=.92)$.

Individual differences. In the previous studies the MDS solutions were obtained by analyzing data averaged across subjects. Although most of these studies included subgroup analyses (e.g., socioeconomic level), the nonmetric scaling techniques were not designed for investigating individual differences and may, therefore, misrepresent the perceptual structure for some subjects (Wish, Deutsch, \& Biener, 1972).

Coxon and Jones (1974a, 1978) and Shubsachs and Davison (1979) have studied individual differences in occupational perceptions. The use of individual difference scaling in such studies provides important information concerning (1) the 


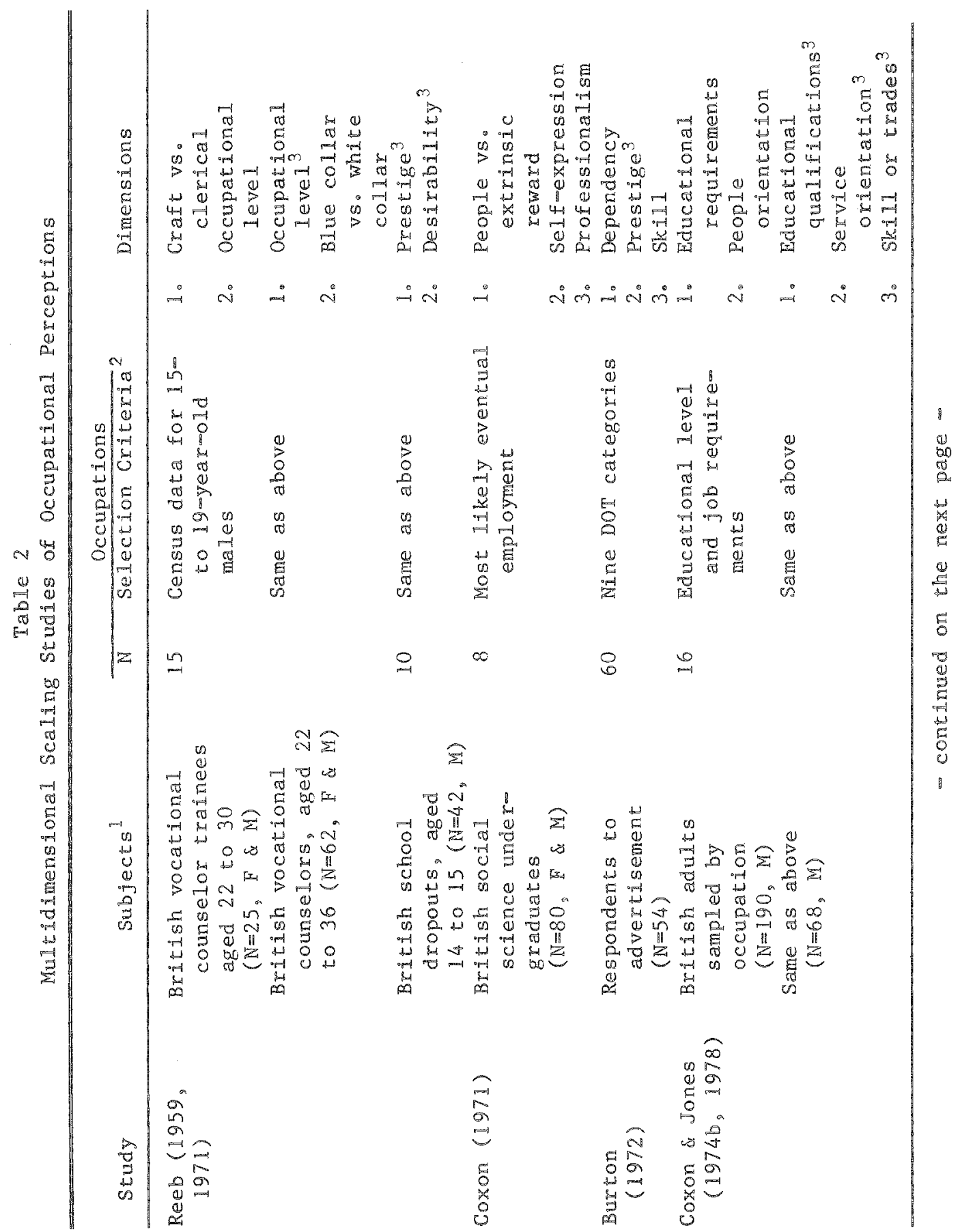




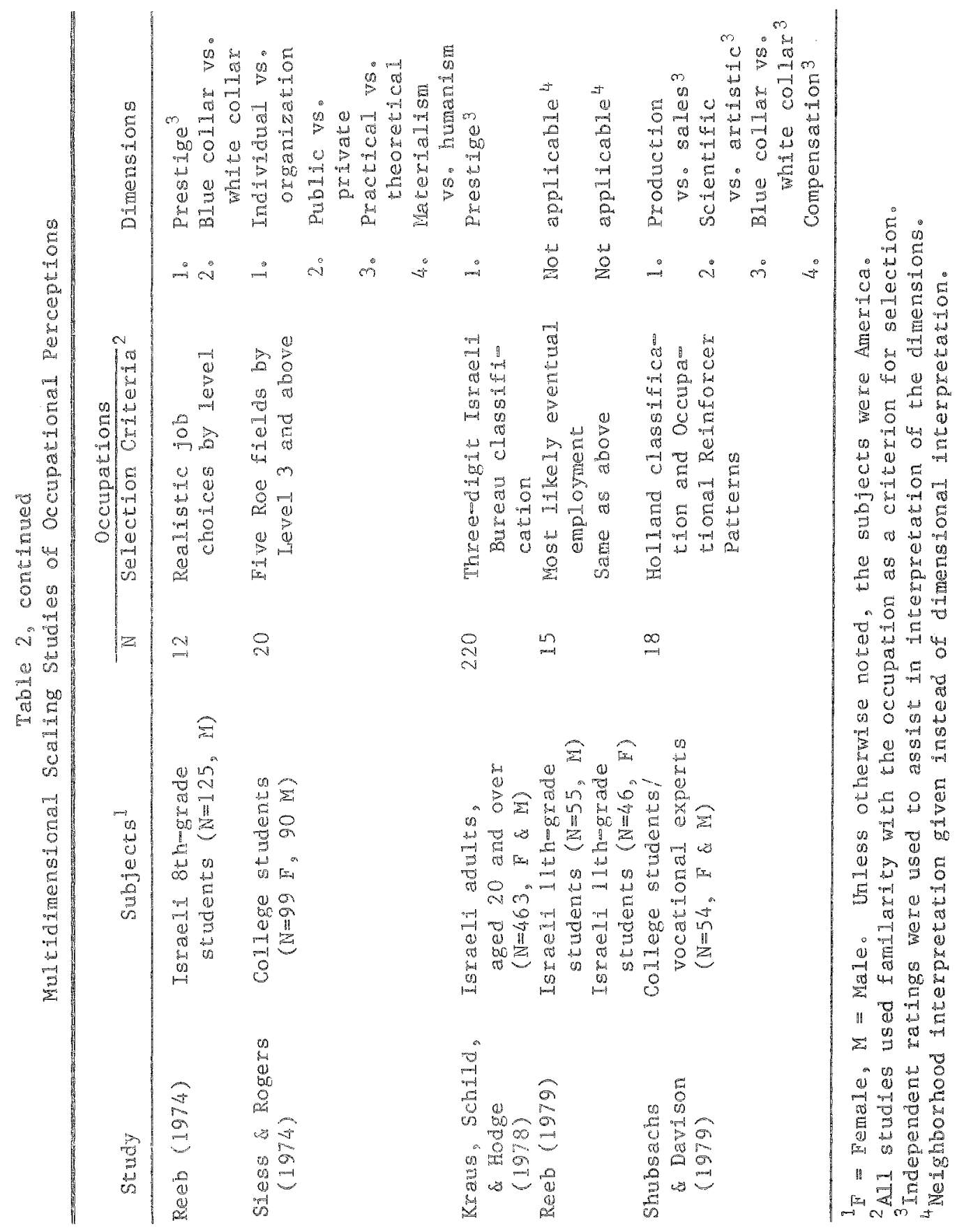

Downloaded from the Digital Conservancy at the University of Minnesota, http://purl.umn.edu/93227. May be reproduced with no cost by students and faculty for academic use. Non-academic reproduction requires payment of royalties through the Copyright Clearance Center, http://www.copyright.com/ 
amount of variance in a subject's data accounted for by the configuration, (2) the pattern and salience of the dimensions, and (3) the importance of the hypothesized attributes. In Coxon and Jones (1974a) the relative weights of occupational groups for their two-dimensional solutions were examined. On the dimension labeled educational requirements, high weights tended to occur among theology students and nurses, whereas low weights characterized building and engineering apprentices and college of education students. On the second dimension, people orientation, the above weights for the occupational group relationships were reversed.

Shubsachs and Davison (1979) compared the relative weights attached by vocational experts, liberal arts students, and engineering students to INDSCAL dimensions. Differences among the subject groups were found only along the compensation dimension; the vocational experts, a group composed of vocational counselors and researchers, attached less importance to this dimension relative to the other groups. As shown in Table 2 Shubsachs and Davison reported a four-dimensional group solution based on the judged similarity of all possible pairs of 18 occupations. For interpretive purposes they regressed 25 hypothesized occupational attributes on the four INDSCAL dimensions. Unfortunately, the number of significant multiple and zero-order correlations confounded the straightforward interpretation of these dimensions. Nevertheless, the regression analysis did demonstrate that occupational reinforcers (Dawis, Lofquist, \& Weiss, 1968; Lofquist \& Dawis, 1969) were an important component of occupational perceptions.

Surprisingly, neither the Coxon and Jones (1974a, 1978) nor Shubsachs and Davison (1979) studies reported finding a prestige dimension. Shubsachs and Davison did, however, report finding a sigmificant multiple correlation $(R=.80)$ between prestige ratings and their four dimensions, a finding which indicated that occupational prestige is represented in the spatial solution. Coxon and Jones relied on a visual examination of the stimulus coordinates and, ostensibly, did not test for a prestige dimension.

Possibly the most extensive applications of MDS to vocational data are the investigations of occupational cognitions conducted by Coxon and Jones (1978, 1979a, 1979b). The results of their extensive analyses, and sometimes obtuse reporting of their findings, are published in three separate volumes and are too extensive to report in detail. Their conclusions conceming the application of individual differences scaling are, however, particularly germane to the present discussion. These conclusions were (1) configurations obtained from scaling pairwise and triadic formats are very similar; (2) while the INDSCAL group space is similar to nonmetric solutions, the INDSCAL solutions require a large number of dimensions; (3) a horseshoe-like structure was observed indicating that one dimension is sufficient to describe the occupational space (see Kruskal \& Wish, 1978, for a more extensive discussion of the horseshoe phenomenon); and (4) subjects' verbalizations of the predicates they used in making occupational judgments indicated intraand inter-individual variations in the level of generality of the judgments.

This latter conclusion resulted from asking subjects to state the way (or ways) in which occupational pairs were alike or different. This method systematically elicits occupational attributes without the imposition of the investigator's preconceptions. Nevertheless, Coxon and Jones (1979a) observed, "Perhaps one of the more striking findings was that the context of a sorting often tells a completely different story from the verbal descriptions. .. . Some people, for example, claimed that social class had no place in their thinking and then proceeded to use it liberally" (p. 189).

Perceptions vs. classification systems. Siess and Rogers (1974) and Reeb (1979) investigated the degree to which the perceived similarity of occupations corresponded to occupational classification systems. These studies are examples of investigations that are concerned with both the identification of the dimensions underlying occupational perceptions (dimensional approach) and the arrangement of occupations in $N$-dimensional space (configural approach).

Siess and Rogers (1974) compared judged similarities made by college freshmen to Roe's (1956) classification system with the expectation that Roe's

Downloaded from the Digital Conservancy at the University of Minnesota, http://purl.umn.edu/93227. May be reproduced with no cost by students and faculty for academic use. Non-academic reproduction requires payment of royalties through the Copyright Clearance Center, http://www.copyright.com/ 
classification would be reflected in the dimensional configuration. Four illustrative occupational titles were selected from five of Roe's eight fields with level held constant. Application of Torgerson's $(1952,1958)$ algorithm to direct similarity judgments provided support for the relative homogeneity of judgments with fields and no support for their postulated circular order.

Reeb (1979) compared direct suitability judgments on 15 occupations made by 101 male and female Israeli students to Roe's (1956), Holland's (1973), and Flanagan, Shaycoff. Richards, \& Claudy's (1971) occupational classifications and to four academic areas. Since the occupations were selected to correspond with the occupations of the students in the four academic areas, it is not surprising that the nonmetric scaling procedure yielded a two-dimensional configuration with occupations grouping into four clusters corresponding to the four academic areas. The comparisons of male and female occupational configurations were accomplished by rotation to best fit of the female stimulus coordinates to the male target matrix. Visual inspection revealed minor variations in location of the occupations for the female and male students.

Reeb (1979) also reported a nonmetric internal analysis of the student's rank-ordered occupational preferences. The MDPREF procedure (Camoll, 1972; Chang \& Carroll, 1974) yielded common stimulus space configurations for each sex, which were rotated for comparison with the occupational similarity solutions. The fields previously found from the similarity judgments remain largely intact on the preference maps; however, the relative locations of the fields and the location of the occupations with each field changed for the male and female students.

Summary. Judgments of the perceived similarity between occupations are efficiently represented by MDS, usually in a two-dimensional space. The dimensions are reproducible within subgroups of samples and are easily interpretable. The studies reviewed above have demonstrated the existence of occupational perceptual structures across a range of samples. In comparison to the configural verification approach, the dimensional approach has been characterized by careful attention to sampling of both occupations and subjects and to tests of prior attribute hypotheses. This greater attention to methodology distinguishes this application of MDS from many other multivariate procedures.

\section{Selection of Occupational Titles}

A consistent finding across studies of occupational perceptions is that subjects organize their perceptions according to prestige. Nevertheless, the consistency of these findings is overshadowed by the variability in the number and types of other dimensions reported in this literature. One possible explanation for this dimensional variability is that the selection of occupational titles affects the number and types of dimensions that result from scaling analysis.

Coxon and Jones (1974b) have discussed three concerns related to the selection of occupational titles: (1) comparability with prior investigations, (2) limitations in the number of stimuli that can be concurrently judged, and (3) adequacy of the stimulus domain sample. The subjects' familiarity with the occupations under investigation is also an important consideration.

Comparability. Comparability with prior investigations refers to a concern about the selection of occupations that are consistent with previous studies. Reeb (1959, 1971), for example, retained his entire set of occupational titles across both investigations, thereby allowing him to directly compare the judged similarities between the 1959 vocational counselor trainee sample and the 1971 experienced vocational counselor sample. Coxon and Jones (1978) selected a set of eight occupational titles from the Hall-Jones (1951) classification system and were able, therefore, to compare their findings with the results of other investigations. This type of cumulative study of a common set of occupational titles encourages programmatic, as opposed to fragmented, research efforts. Unfortunately, the acceptance of a uniform set of titles has yet to occur, although it seems to be a desirable goal.

Number of stimuli. The number of occupational titles used in any investigation varies with the type of experimental task. In general, occu-

Downloaded from the Digital Conservancy at the University of Minnesota, http://purl.umn.edu/93227. May be reproduced with no cost by students and faculty for academic use. Non-academic reproduction requires payment of royalties through the Copyright Clearance Center, http://www.copyright.com/ 
pational perception research has used a category rating task in conjunction with a complete paired comparison design. As the number of occupational titles increases, however, the number of pairs, $I(I-1) / 2$, increases rapidly, thereby placing limits on the number of occupations that subjects can be expected to judge within the paired comparison format. With the use of incomplete designs (Torgersorn, 1958), however, the number of stimuli can be increased substantially. Recent work by MacCallum (1978) and Spence and Domoney (1974) discusses the advantages of different types of incomplete designs for nonmetric MDS. With large numbers of occupational stimuli (that is, greater than 35), sorting strategies such as those used by Burton (1972) are necessary (see Rosenberg \& $\mathrm{Kim}$, 1975).

Adequacy of the stimuli. It is important to recall that the set of occupational tites in a particular study is a sample from a large domain. Existing occupational classifications have ofter served as definitions of the domain in studies of occupational perceptions. The adequacy of the ser of occupational titles used in a study then becomes a sampling issue. None of the studies so far reviewed have reported drawing a random sample of occupational titles. The most frequently encountered sampling strategy involves the experimenter selecting occupations that are judged to be representative of the domain in question. The major advantages of this nonprobability sampling technique are convenience and economy. On the other hand, this procedure lacks ar objective verification of the representativeness of the sample. Given an unrepresentative sample, the generalizability of the findings becomes an issue. These considerations become particularly salient when the domain under investigation is extremely large, e.g., The Dictionary of Occupational Titles (U.S. Department of Labor, 1977).

Several studies have attempted to define the occupational domain by simply asking subjects to list occupations. Burton (1972), using a free recall task, reported that subjects listed only high prestige and creative occupations. Reeb (1974) found no relationship between census data and subjects' listings of occupations in response to the question, " $\mathrm{In}$ what jobs do people most commonly work?" (p. 128). These wo studies indicate little correspondence between an individual's naturalistic occupational classifications and those imposed by imvestigators. The effect of this discrepency has not been explored, and although it is perhaps only an interesting observation at this point, it seems worthy of future investigation.

Familiarity with the stimuli. Very little is known about the effects of subjects' occupational familiarity on scaling solutions. Of the nine occupational perception studies reviewed herein, only one directly assessed the subject's familiarity with the investigated occupations (Shubsachs \& Davison, 1979).

Research on vocational maturicy (Westbrook, 1983 ) and cognitive complexity (Haase, Reed, \& Winer, 1979) indicates that occupational knowledge (accuracy of information) is related to appropriateness of vocational choice and, further, that occupational information decreases rather than increases cognitive complexity in the occupational realm. Thus, the question of familiarity with occupations is an issue considerably more complex than many investigators had initially anticipated. At the minimum, therefore, it is suggested that researchers incorporate famillarity checks into MDS designs and regress the familiarity ratings over the coordinates of the configuration. This procedure would indicate the manner in which familiarity effects the scaling solution.

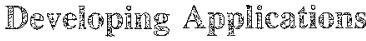

Several topics within vocational psychology represent areas in which MDS analysis has, to date, been only minimally applied. A number of these topics appear to represent promising new directions for vocational research and areas where MDS techniques can be frupifully applied. One such direction is exemplified by a study investigating stage theories of vocational development (Jepsen \& Grove, 1981). Hitherto, vocational stage models have largely been untested. Tests that have been conducted consisted of demonstrating mean differences on vocational maturity indices among age groups. Jepsen and Grove applied MDS procedures to measures

Downloaded from the Digital Conservancy at the University of Minnesota, http://purl.umn.edu/93227. May be reproduced with no cost by students and faculty for academic use. Non-academic reproduction requires payment of royalties through the Copyright Clearance Center, http://www.copyright.com/ 
of Tiedeman and O'Hara's (1963) vocational decision-making paradigm. The authors reported two related purposes for their study: first, to test the hypothesis that vocational decision-making stages follow the exploration, crystallization, choice, and clarification stages postulated by Tiedeman and $\mathrm{O}^{\prime} \mathrm{Hara}$; and second, to extend earlier work on $\mathrm{Lav}$ ison's (1977) metric unfolding model. The results of the nonmetric scaling generally supported Tiedeman and O'Hara's stage order, with the exception of a reversal of the choice and clarification stages.

The authors" hypothesis regarding the dominance of the vocational decision-making stages and the association of the student's responses with a single stage was not supported. A major finding of the study was the usefulness of the metric unfolding model for testing stage theories with cross-sectional data. Although the authors noted that the unfolding procedure is not a substitute for longitudinal data, its use in this and related studies testing stage sequence models is amply supported (see Davison, 慰ing, Kitchener, \& Parker, 1980; Davison, Robbins, \& Swanson, 1978).

A second study (Krau, 1982), examining vocational stages, assessed a career model for immigrants with two samples-one recent immigrant group and one group assessed 5 years after immigration. The analysis, using Gurtman-Lingoes nonmetric $S S A$, is a good example of a data reduction application where the intent is to represent the similarity data in a simpler form. The hypothesized model was supported by both the GutmanLingoes analysis and the multiple regression of criterion variables on a number of success predictors. Even though the investigation is of interest, since little empirical work examines applications of career stage models to an immigrant sample, the use of nonmetric scaling procedures provides minimal information compared to that which would result from other data analytic techniques. Application of Davison's unfolding model, for example, would provide a better test of this career stage model.

Another promising area for the application of MDS is the investigation of the structure of job satisfaction. Three studies were located (Ben-Porat, 1978, 1981; Katz \& Maanen, 1977). In an exploratory study, Ben-Porat (1978) showed that job factors are arranged in a circular order divided by extrinsic and intrinsic dimensions. In an extension of this study, Ben-Porat (1981) evaluated Schnieder and Locke's (1971) two-factor theory of job satisfaction by embedding event and agent as two domain facets of a job satisfaction content universe (see Guttman, 1954, and Shapira and Zevulun, 1979 , for a discussion of facet analysis). Based on an Israeli sample of 104 blue-collar workers from eight industrial organizations, an intercorrelation matrix of 11 items of job satisfaction and one item measuring overall satisfaction were submitted to the SSA1 program. The results confirmed an a priori hypothesis of a radex structure when job satisfaction is defined by two domain facets.

Katz and Maanen (1977) examined the relationship between components of work satisfaction and a number of work environment design variables (e.g., assigned tasks, work assistance, and communications). Work satisfaction was measured by a modified version of the Minnesota Satisfaction Questionnaire (Dawis \& Weitzel, 1974) administered to 3,080 subjects from four government organizations. The authors subsequently applied a nonmetric scaling procedure (TORSCA; Torgerson, 1965; Young \& Torgerson, 1967) to only the job satisfaction intercorrelation matrix. Three distinct clusters (job properties, interaction context, and organizational policies) were identified with a visual inspection of the two-dimensional solution and the application of a neighborhood interpretation. The two dimensions were interpreted as a short-versus long-tem element in job satisfaction and the traditional intrinsic-extrinsic dimension.

The primary advantage of MDS as applied in studies of job satisfaction is that nonmetric procedures typically yield fewer dimensions than factor analysis, thereby providing greater simplicity and facilitating interpretation. A potential disadvantage is the influence of investigator bias in visual interpretation. A possible alternative to exploratory uses of nonmetric scaling is the use of confirmatory scaling procedures (Carroll \& Arabie, 1980; Davison, 1983). At this point, however, the advantages associated with confirmatory procedures are limited by the lack of an agreed upon measure of hî. 
A research area related to job satisfaction is the topic of work outcomes, also known as needs and values in the counseling literature. A good example of a dimensional application of MDS in this area is a study by Billings and Cornelius (1980). The purpose of this exploratory study was to examine the perceptual structure of work outcomes and to demonstrate the appropriateness of MDS in this effort. The authors developed two questionnaires, one based on similarity judgments and the other requiring likelihood judgments. Both questionnaires consisted of paired comparisons of the 21 work outcomes used in the Dyer and Parker (1975) survey and asked the subjects to rate eight hypothesized attributes for each of the 21 work outcomes.

Using the individual differences weighted Euclidian model incorporated in the ALSCAL program (Takane, Young, \& de Leeuw, 1977), the authors determined the dimensionality by correlating the stimulus coordinates of the similarity spaces with the likelihood spaces. The cross-correlations that best met the requirements for convergent and divergent validity indicated a three-dimensional solution for both the likelihood and similarity data. The fit of the eight attribute vectors indicated that the three dimensions were best interpreted as "societal values," "underlying needs," and "extent inherent in work"; no support was found for the internal-external categorization of work outcomes.

This later finding is particularly interesting in light of the study by Ronen, Kraut, Lingoes, and Aranya (1979). This investigation examined the intercorrelations among importance ratings of 14 work outcomes made by 800 salesmen and 1,800 repairmen using the SSA-I program. A twodimensional solution was derived separately for the salesmen and repairmen occupational groups; the COAs were .14 and .15 , respectively. Neighborhood interpretations supported several different a priori groupings - intrinsic/extrinsic, Maslow's need hierarchy, and Alderfer's existence and relatedness needs-an eloquent demonstration of the pitfalls of visual interpretation.

These developing applications are not meant to be an exhaustive representation of multidimensional scaling applications in vocational research.
Indeed, a number of additional applications are evident in the literature, including the areas of occupational reinforcers (Rounds, Shubsachs, Dawis, \& Lofquist, 1978), perceptions of vocational counseling roles (Brook, 1979), potential work mobility (Aranya, Jacobson, \& Shye, 1976), design of work environments (Kenny \& Canter, 1981), job analysis and classification (Brown, 1967; Sacket, Cornelius \& Carron, 1981; Smith \& Siegel, 1967), and career preferences (Soutar \& Clarke, 1983). The diversity of these applications bodes well for the future of multidimensional scaling in vocational psychology research.

\section{嫼eferences}

American College Testing Program. Handbook for the ACT career planning program. Iowa City IA: Author, 1968.

Aranya, N., Jacobson, D., \& Shye, S. A Smallest Space Analysis (SSA) of potential work mobility. Multivariate Behavioral Research, 1976, 11, 165-173.

Ben-Porat, A. The correlation matrix of job satisfaction treated by Guttman Smallest Space Analysis. Psychological Reports, 1978, 42, 784-786.

Ben-Porat, A. Event and agent: Towards a structural theory of job satisfaction. Personnel Psychology, 1981, $34,523-534$

Billings, R. S. \& Comelius, E. T. Dimensions of work outcomes: A multidimensional scaling approach. $P$ ersonnel Psychology, 1980, 83, 151-161.

Brook, J. A repertory grid analysis of perceptions of vocational counseling roles. Journal of Vocational Behavior, $1979,15,25-35$.

Brown, $\mathrm{K}$. R. Job analysis by multidimensional scaling. Joumal of Applied Psychology, 1967, 51, 469-475.

Burton, M. Semantic dimensions of occupational names. In $\mathbf{A} . \mathbb{K}$. Romney, R. N. Shepard, \& S. B. Nerlove (Eds.), Multidimensional scaling: Theory and applications in the behavioral sciences (Vol. 2). New York: Seminar Press, 1972.

Campbell, D. P. Manual for the Strong-Campbell Interest Inventory (2nd ed.). Stanford CA: Stanford University Press, 1977.

Carroll, J. D. Individual differences and multidimensional scaling. In $\mathbb{R}$. N. Shepard, A. K. Romney, \& S. B. Nerlove (Eds.), Multidimensional scaling: Theory and applications in the behavioral sciences (Vol. 1). New York: Seminar Press, 1972.

Carroll, J. D., \& Arabie, P. Multidimensional scaling. Annual Review of Psychology, 1980, 31, 607-649. 
Chang, J. I., \& Carroll, J. D. How to use MDPREF, a computer program for multidimensional analysis of preference data. Murray-Hill NJ: Bell Laboratories, 1974.

Cole, N.S. On measuring the vocational interests of women. Journal of Counseling Psychology, 1973, 20, 105-112.

Cole, N. S., \& Cole, J. W. L. An analysis of spatial configuration and its application to research in higher education (ACT Research Report No. 35.) Iowa City IA: The American College Testing Program, 1970.

Cole, N. S., Whitney, D. R., \& Holland, I. L. A spatial configuration of occupations. Joumal of Vocational Behavior, 1971, I, 1-9.

Cooley, W. W., \& Lohnes, P. R. Multivariate data analysis. New York: Wiley, 1971.

Coxon, A. P. M. Occupational attributes: Constructs and structure. Sociology, 1971, 5, 335-354.

Coxon, A. P. M., \& Jones, C. L. Occupational similarities: Subjective aspects of social stratification. Quality and Quantiry, 1974, 8, 139-157. (a)

Coxon, A. P. M., \& Jones, C. L. Problems in the selection of occupational titles. Sociological Review, $1974,22,369-384$. (b)

Coxon, A. P. M., \& Jones, C. L. The images of occupational prestige. New York: St. Martin, 1978.

Coxon, A. P. M., \& Jones, C. L. Class and hierarchy: The social meaning of occupations. New York: St. Martin, 1979. (a)

Coxon, A. P. M., \& Jones, C. $\mathbb{L}$. Measurement and meaning: Techniques and methods of siudying occupational cognitions. New York: St. Martin, 1979. (b)

Davison, M. L. On a unidimensional, metric unfolding model for attitudinal and developmental data. Psychometrika, 1977, 42, 523-548.

Davison, M. L. Multidimensional scaling versus factor analysis of tests and items. Paper presented at the annual meeting of the American Psychological Association, Los Angeles, August 1981.

Davison, M. L. Multidimensional scaling. New York: Wiley, 1983.

Davison, M. L., King, P. M., Kitchener, K. S., \& Parker, C. A. The stage sequence concept in cognitive and social development. Developmental Psychology, $1980,16,121-131$.

Davison, M. L. Robbins, S., \& Swanson, D. Stage structure in objective moral judgments. Developmental Psychology, 1978, 14, 137-146.

Dawis, R. V. Measuring interests. In D. A. Payne (Ed.), New directions for testing and measurement: Recent developments in affective measurement. San Francisco: Jossey-Bass, 1980

Dawis, R. V., Lofquist, L. H., \& Weiss, D. J. A theory of work adjustment: A revision (Minnesota Studies in Vocational Rehabilitation, No. 23). Minneapolis: Uni- versity of Minnesota, Vocational Psychology Research, 1968.

Dawis, R. V., \& Weitzel, W. Worker attitudes and expectations. In $\mathrm{O}$. Yoder \& $\mathrm{H}$. G. Heneman, Jr. (Eds.), Handbook of personnel management and industrial relations. Washington DC: Bureau of National Affairs, 1974.

Dipboye, W. J., \& Anderson, W. F. Occupational stereotypes and manifest needs in high school students. Journal of Counseling Psychology, 1961, 8, 296-304.

Dyer, L., \& Parker, D. F. Classifying outcomes in work motivation research: An examination of the intrinsicextrinsic dichotomy. Journal of Applied Psychology, $1975,60,455-458$.

Edwards, K. I., Nafziger, D. H., \& Holland, J. L. Differentiation of occupational perceptions among different age groups. Journal of Vocational Behavior, 1974, 4, 311-318.

Ekman, G. Dimensions of color vision. Journal of Psychology, 1954, 38, 467-474.

Feldman, S., \& Meir, E. I. Measuring women's interests using Holland's vocational classification. Journal of Vocational Behavior, 1976, 9, 345-353.

Flanagan, J. C., Jr., Shaycoff, M. F., Richards, J. M., Jr., \& Claudy, J. G. Five years after high school. Palo Alto CA: American Institutes for Research, 1971.

Gati, I. A hierarchical model for the structure of vocational interests. Journal of Vocational Behavior, 1979 , 15, 90-106.

Gati, $\mathbb{I}$. Testing models for the structure of vocational interests. Journal of Vocational Behavior, 1982, 21, $164-182$.

Gonyea, G. G., \& Lunneborg, C. E. A factor analyuic study of perceived occupational similarity. Journal of Applied Psychology, 1963, 47, 166-172.

Gottfredson, L. S. Vocational research priorities. The Counseling Psychologist, 1982, 10, 69-84.

Grunes, W. F. Looking at occupations. Journal of Abnormal and Social Psychology, 1957, 54, 86-92.

Guilford, J. P., Christensen, P. R., Bond, N. A., \& Sutton, M. A. A factor analytic study of human interests. Psychological Monographs, 1954, 68 (4, Whole No. 375)

Guttman, $\mathbb{L}$. An outline of some new methodology in social research. Public Opinion Quarterly, 1954, 18, 395-404.

Guttman, L. A generalized nonmetric technique for finding the smallest coordinate space for a configuration of points. Psychometrika, 1968, 33, 469-506.

Hiase, R. F., Reed, C. F., \& Winer, J. I. Effect of positive, negative, and mixed occupational information on cognitive and affective complexity. Joumal of Vocational Behavior, 1979, 15, 294-302.

Hall, J., \& Jones, D. C. Social grading of occupations. British Joumal of Sociology, 1951, 1, 31-35. 
Hanson, G. R., \& Cole, N. S. (Eds.), The vocational interests of young adults (Monograph No. 11). lowa City IA: American College Testing Program, 1973.

Hartmann, M. The grading of occupations by sociologists. Paper presented at the annual meeting of the Israeli Sociological Association, 1975. (in Hebrew)

Holcomb, W. R., \& Anderson, W. P. Vocational guidance research: A five-year overview. Jounnal of $\mathrm{Vo}$ cational Behavior, 1977, 10, 341-346.

Holland, I. L. Professional manual for the Self-Directed Search. Palo Alto CA: Consulting Psychologists Press, 1972 .

Holland, J. L. Making vocational choices: A theory of careers. Englewood Cliffs NJ: Prentice Hall, 1973.

Holland, J. L. Vocational preferences. In M. D. Dunnette (Ed.), Handbook of industrial and organizational psychology. Chicago: Rand McNally, 1976.

Holland, J. L. Professional manual for the Self-Directed Search. Palo Alto CA: Consulting Psychologists Press, 1979.

Jepsen, D. A., \& Grove, W. M. Stage order and dominance in adolescent vocational decision-making processes: An empirical test of the Tiedeman-O'Hara paradigm. Journal of Vocational Behavior. 1981, 18, $237-251$.

Katz, R., \& Maanen, J. V. The loci of work satisfaction: Job, interaction, and policy. Human Relations, 1977 , $30,469-486$.

Kenny, C., \& Canter, D. A facet structure for nurses' evaluation of ward designs. Journal of Occupational Psychology, 1981, 54, 93-108.

Krau, E. The vocational side of a new start in life: A career model of immigrants. Joumal of Vocational Behavior, 1982, 20, 313-330.

Kraus, V., Schild, E. O., \& Hodge, R.W. Occupational prestige in the collective conscience. Social Forces, 1978, 56, 900-918.

Krumhansi, C. L. Concerning the applicability of geometric models to similarity data: The interrelationship between similarity and spatial density. Psychological Review, 1978, 85, 445-463.

Kruskal, J. B. Multidimensional scaling by optimizing goodness of fit to a nonmetric hypothesis. Psychometrika, 1964, 29, 1-27; 115-129.

Kruskal, J. B. The relationship between multidimensional scaling and clustering. In I. Van Ryzin (Ed.), Classification and clustering. New York: Academic Press, 1977.

Kruskal, I. B., \& Carmone, F. How to use M-D-SCAL (Version 5M) and other useful information. Murray Hill NJ: Bell Laboratories, 1969.

Kruskal, J. B., \& Wish, M. Multidimensional scaling. Beverly Hills CA: Sage, 1978.

Lingoes, J. C. An IBM 7090 program for Guttman-Lingoes Smallest Space Analysis-I. Behavioral Sciences,
$1965,10,183-184$.

Lofquist, L. H., \& Dawis, R. V. Adjustment to work. New York: Appleton-Century-Crofts, 1969.

Lamneborg, C. E., \& Lunneborg, P. W. Factor structure of the vocational interest models of Roe and Holland. Journal of Vocational Behavior, 1975, 7, 313-326.

Lunneborg, P. W. Manual for the Vocational Interest Inventory. Seattle: University of Washington, Educational Assessment Center, 1975.

Luxenberg, M., \& Zevon, M. A. The structure of mood covariation patterns over time via an individual difference multidimensional scaling analysis. Paper presented at the annual meeting of the Psychometric Society, Montreal, Canada, 1982.

MacCallum, R. C. Relations between factor analysis and multidimensional scaling. Psychological Bulletin, 1974, 81, 505-516.

MacCallum, R. C. Recovery of structure in incomplete data by ALSCAL. Psychometrika, 1978, 44, 69-74.

Meir, E. I. The structure of occupations by interestsA Smallest Space Analysis. Journal of Vocational Behavior, 1973, 3, 21-31.

Meir, E. I., Bar, R., Lahav, G. , \& Shalhevet, R. Interest inventories based on Roe's classification modified for negative respondents. Joumal of Vocational Behav. ior, 1975, 7, 127-133.

Meir, E. I., \& Barak, A. A simple instrument for measuring vocational interests based on Roe's classification of occupations. Joumal of Vocational Behavior, $1974,4,33-42$.

Meir, E. I., \& Ben-Yehuda, A. Inventories based on Roe and Holland yield similar results. Journal of $\mathrm{VO}$ cational Behavior, 1976, 8, 269-274.

Meir, E. I., Sohlberg, S., \& Barak, A. A cross-cultural comparison of the structure of vocational interests. Journal of Cross-Cultural Psychology, 1973, 4, 501508.

Osipow, S. H. Theories of career development (3rd ed.). Englewood Cliffs NJ: Prentice-Hall, 1983.

Prediger, D. J. Dimensions underlying Holland's hexagon: Missing link between interests and occupations? Journal of Vocational Behavior, 1982, 21, 259-287.

Reeb, M. How people see jobs: A multidimensional analysis. Occupational Psychology, 1959, 33, 1-17.

Reeb. M. Multidimensional perceptions by counselors and 14-year-old boys of suitability for jobs, and their prestige and desirability. Occupational Psychology, $1971,45,233-242$.

Reeb, M. The perceptions of occupational structurean intervening variable in vocational behavior. Journal of Vocational Behavior, 1974, 4, 125-137.

Reeb, M. Occupational perception and school stream in relation to job classifications, preferences, and prestige for 17-year-old girls and boys. Journal of OCcupational Psychology, 1979, 52, 113-127. 
Roe, A. The psychology of occupations. New York: Wiley, 1956.

Roe, A., \& Klos, D. Occupational classification. Counseling Psychologist, 1969, 1, 84-89.

Ronen, S., Kraut, A. I., Lingoes, J. C., \& Aranya, N. A nonmetric scaling approach to taxonomies of employee work motivation. Multivariate Behavioral Research, 1979, 14, 387-401.

Rosenberg, S., \& Kim, M. P. The method of sorting as a data-gathering procedure in multivariate research. Multivariate Behavioral Research, 1975, 10, 489502.

Rounds, J. B., Jr., Davison, M. L., \& Dawis, R. V. The fit between Strong-Campbell Interest Inventory General Occupational Themes and Holland's hexagonal model. Journal of Vocational Behavior, 1979, 15, 303-315.

Rounds, J. B., Jr., \& Dawis, R. V. Factor analysis of Strong Vocational Interest Blank items. Journal of Applied Psychology, 1979, 64, 132-143.

Rounds, J. B., Jr., \& Dawis, R. V. Multidimensional scaling solutions for the Self-Directed Search (1979 ed.). Unpublished manuscript, 1980.

Rounds, J. B., Ir., Shubsachs, A. P. W., Dawis, R. V., $\&$ Lofquist, L. H. A test of Holland's environmental formulations. Joumal of Applied Psychology, 1978, $63,609-616$

Sackett, P. R., Cornelius, E. T., \& Carron, T. J. A comparison of global judgment vs. task oriented approaches to job classification. Personnel Psychology, $1981,34,791-804$.

Sattath, S., \& Tversky, A. Additive similarity trees. Psychometrika, 1977, 42, 319-345.

Schneider, J., \& Locke, E. A. A critique of Herzberg's incident classification system and a suggested revision. Organizational Behavior and Human Performance, 1971, 6, 441-457.

Shapira, Z., \& Zevulun, E. On the use of facet analysis in organizational behavior research: Some conceptual considerations and an example. Organizational Behavior and Human Performance, 1979, 23, 411-428.

Shepard, R. N. Introduction to volume 1. In R. N. Shepard, A. K. Romney, \& S. B. Nerlove (Eds.) Multidimensional scaling. Theory and applications in the behavioral sciences (Vol. 1). New York: Seminar Press, 1972.

Shepard, R. N., \& Arabie, P. Additive clustering: Representation of similarities as combinations of discrete overlapping properties. Psychological Review, 1979 , $86,87-123$.

Shubsachs, A. P. W., \& Davison, M. L. Individual differences in perceptions of occupations and occupational reinforcers. Journal of Occupational Psychology, 1979, 52, 299-310.

Siess, T. F., \& Rogers, T. B. Roe's classification and the multidimensional nature of occupational perceptions. Journal of Vocational Behavior, 1974, 4, 403415.

Smith, R. J., \& Siegel, A. I. A multidimensional scaling analysis of the job of civil defense direction. Journal of Applied Psychology, 1967, 51, 476-480.

Soutar, G. N., \& Clarke, A.W. Examining business students' career preferences: A perceptual space approach. Joumal of Vocational Behavior, 1983, 23, 11-21.

Spence, I., \& Domoney, D. W. Single subject incomplete designs for nonmetric multidimensional scaling. Psychometrika, 1974, 39, 469-490.

Stone, L. A., \& Bassett, G. R. The MEDEX occupation concept in subjective medical occupation-profession multidimensional space. Psychological Reports, 1972, 31, 167-174.

Takane, Y., Young, F. W., \& de Leeuw, J. Nonmetric individual differences multidimensional scaling: An alternating least squares method with optimum scaling features. Psychometrika, 1977, 42, 7-67.

Tiedeman, D. V., \& O'Hara, R. P. Career development: Choice and adjustment. New York: College Entrance Examination Board, 1963.

Torgerson, W. S. Multidimensional scaling: I. Theory and method. Psychometrika, 1952, 17, 401-419.

Torgerson, W. S. Theory and methods of scaling. New York: Wiley, 1958.

Torgerson, W. S. Multidimensional scaling of similarity. Psychometrika, 1965, 30, 379-393.

Tversky, A., \& Gati, I. Studies of similarity. In E. Rosch \& B. B. Lloyd (Eds.), Cognition and categorization. Hillsdale NJ: Erlbaum, 1978.

U.S. Department of Labor. Dictionary of Occupational Titles (4th ed.). Washington DC: U.S. Government Printing Office, 1977.

Wakefield, J. A., \& Doughtie, E. B. The geometric relationship between Holland's personality typology and the Vocational Preference Inventory. Journal of Counseling Psychology, 1973, 20, 513-518.

Westbrook, $\mathbb{B}$. W. Career maturity: The concept, the instrument, and the research. In W. B. Walsh \& S. H. Osipow (Eds.), Handbook of vocational psychology (Vol. 1). Hillsdale NJ: Erlbaum, 1983.

Wish, M., Deutsch, M., \& Biener, L. Differences in perceived similarity of nations. In $\mathrm{A} . \mathbb{K}$. Romney, R. N. Shepard, \& S. B. Nerlove (Eds.), Multidimensional scaling: Theory and application in the behavioral sciences (Vol. 2). New York: Seminar Press, 1972.

Young, F. W., \& Torgerson, W. S. TORSCA, a Fortran IV program for Shepard-Kruskal multidimensional scaling analysis. Behavioral Science, 1967, 12, 498.

Zevon, M. A., Luxenberg, M., \& Rounds, J. B., Jr. Mood covariation patterns over time: A comparison 
of multidimensional scaling and factor analytic solutions. Manuscript submitted for publication, 1983.

\section{Acknowledgments}

Preparation of this paper was supported in part by the Spencer Foundation. The authors thank Elaine Shisler for her assistance in the preparation of the manuscript.

\section{Author's Address}

Send requests for reprints or further information to James B. Rounds, Jr., Department of Counseling and Educational Psychology, 416 Christopher Baldy Hall, SUNYAB, Buffalo NY 14260, U.S.A.

Downloaded from the Digital Conservancy at the University of Minnesota, http://purl.umn.edu/93227. 